\title{
A water suppression model for wildfires
}

\author{
$\underline{\text { J.E. Hilton }}^{a}$ (D), A. Sullivan ${ }^{b}$, M. Plucinski ${ }^{b}$ and W. Swedosh ${ }^{c}$ \\ ${ }^{a}$ Data61, CSIRO, Clayton South, VIC 3169, Australia \\ ${ }^{b}$ Land \& Water, CSIRO, Black Mountain, ACT 2601, Australia \\ ${ }^{c}$ Land \& Water, CSIRO, Clayton South, VIC 3169, Australia \\ Email:james.hilton@csiro.au
}

\begin{abstract}
The ability to model water suppression efforts on wildfires is useful for both operational firefighting as well as testing control and containment strategies. Models developed to date have used heat energy balance relations to estimate the flow of water needed to extinguish a wildfire, but these have some limitations. These include expressing extinguishment criteria in the form of a steady state water flow relation and the inability to model the heat retention within the fuel bed. The modelling of heat retention is necessary as although water can cool the bed below the point of ignition, once the water has evaporated the bed can potentially re-ignite due to residual heating from the lower layers. Here we detail a water suppression model based on temperature and heat flow within the bed. The model is dynamic, can be applied spatially for operational wildfire simulations and allows re-ignition of the fire. The model is applied within the Spark wildfire modelling framework, a basic example scenario of which is shown in Figure 1. Here a point ignition develops into an ellipse under idealised conditions (the colour representing the temperature of the upper bed) and is subject to water suppression applied in a line (the density of which is shown as the vertical grayscale line). The temperature of the upper bed rapidly drops as the water is applied (600 s), extinguishing the fire. However, the amount of water is insufficient to maintain the upper bed below the ignition temperature of the fuel causing reignition $(608 \mathrm{~s})$ and a subsequent breakout over the suppression region $(700 \mathrm{~s})$. The model is a simplification of the complexities of wildfire combustion and relies on several physical parameters, some of which are difficult to measure and must be estimated. Despite these limitations the model provides a physically based approach to wildfire water suppression which could be used, once fully validated, to inform or direct suppression activities and strategies.
\end{abstract}

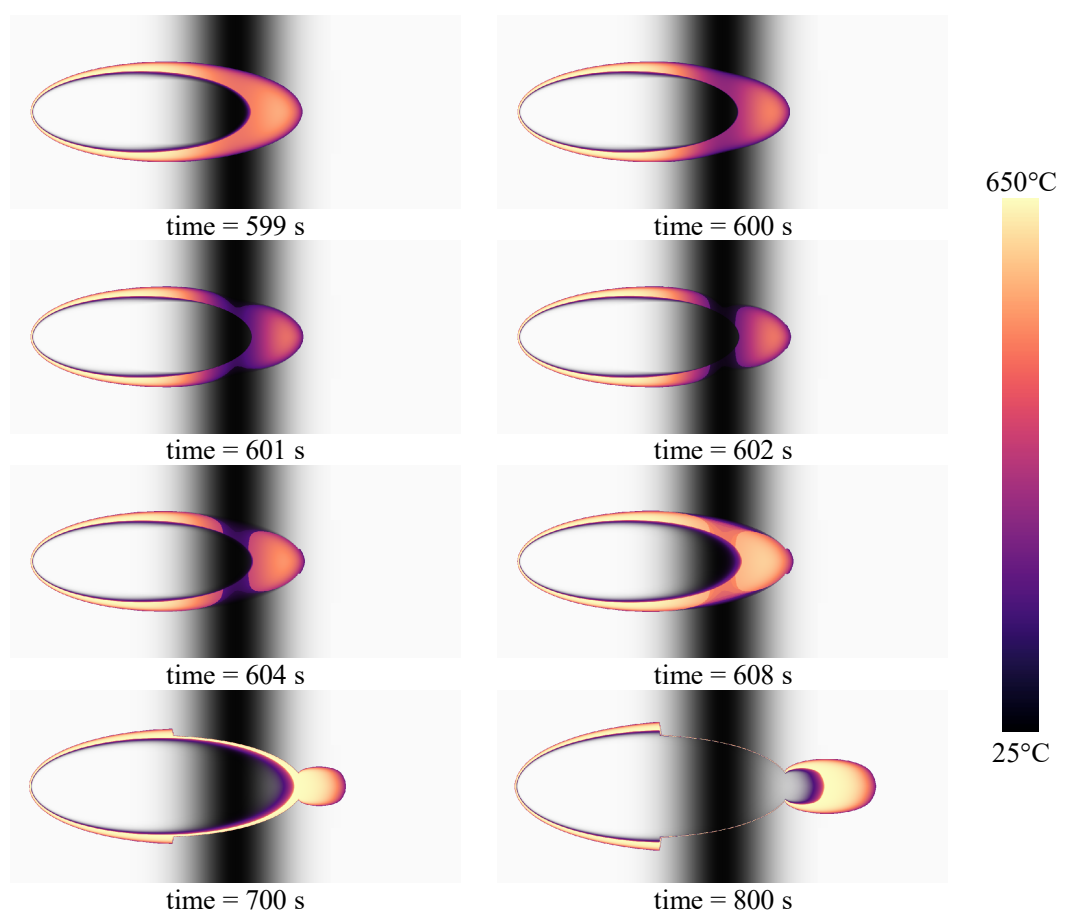

Figure 1. Upper bed temperature for idealized elliptical fire with a fuel density of $12.5 \mathrm{~kg} \mathrm{~m}^{-3}$. The grayscale shading represents mass of water per unit area from Eq. (8) where black is $1.42 \mathrm{~L} \mathrm{~m}^{-2}$.

Keywords: $\quad$ Wildfire modelling, suppression, computational fluid dynamics, Spark 


\section{INTRODUCTION}

Controlling a wildfire is paramount in firefighting and a variety of suppression methods can be used to extinguish or reduce the intensity of a firefront. These include direct attack methods in which suppressants (e.g. water and water additives) are applied directly to flames or indirect methods in which availability of fuels in the path of a fire is reduced through use of chemical retardants, construction of control lines or backburning. Direct attack is often conducted in stages with an initial knock down of flames undertaken to reduce its intensity by slowing or stopping fire spread, followed by a more complete extinction of residual combustion (Plucinski 2019). Computational models used to predict the likely progression of wildfires can relatively easily incorporate indirect suppression methods by appropriately modifying spatial fuel layers or introducing unburnable barriers into the model. However direct suppression methods are more difficult to incorporate into models as the interactions between the agent used to suppress the fire and the combustion of the fire must be simulated in some way. Although this may be more feasible in a physics-based computational fluid dynamics wildfire model where computational requirements are not limiting, it is more difficult to apply in simulation models intended for operational planning and management which are bound by strict time demands.

In this study we present a simplified model for the suppression of a firefront using water as the suppressant. It models the application and subsequent evaporation of water from a combusting fuel bed, with the potential for cooling the bed below the critical ignition temperature for self-sustained combustion. A model to estimate the amount of water required to actively extinguish a wildfire from physical principals was developed by Hansen (2012). This model was based on Spalding B number theory to give mass burning rates and utilised the assumption of external heat flux being radiation dominated. Hansen's relations allow a required mass flow rate of water to be determined for a particular Byram fireline intensity in the active flaming zone (Byram 1959).

Despite the theoretical basis of the Hansen model, it assumes the ability to extinguish a fire is based on removing the radiative component, thereby reducing the external heat flux incident on adjacent fuel to below the critical value required for self-sustaining combustion. In practice, however, a biomass fuel bed will retain heat after flaming combustion has been halted due to competitive exothermic combustion reactions (Sullivan 2017), and if this is sufficient to entirely evaporate any water and the heat conducted to the surface is less than the critical ignition temperature of the fuel, the fire will re-ignite. The water suppression model presented here is a substantial simplification of heat transfer processes involved in wildfires being based on fuel temperature rather than heat flux. As a result, it is relatively straightforward to implement in an operational wildfire spread tool. The model can also be applied spatially; that is, with differing water amounts in different areas. It should be noted that the act of suppression in this paper is the maintained extinguishment of the flame front and the prevention of further spread of the fire, not the total cessation of all combustion pathways within the fuel bed. Complete cessation of combustion in biomass fuels is difficult to achieve, requiring manual clearing of fuel and addition of substantial volumes of water, usually carried out as part of 'mopping up' operations after fires.

\section{METHODLOGY}

The temperature within a fuel bed in the vertical direction, $T(\mathrm{~K})$, is described by the heat equation (Drysdale, 1985):

$$
\frac{\partial T}{\partial t}=\frac{h}{c_{b} \rho_{b}} \frac{\partial^{2} T}{\partial z^{2}}+S
$$

where $h\left(\mathrm{~J} \mathrm{~s}^{-1} \mathrm{~m}^{-1} \mathrm{~K}^{-1}\right)$ is a heat transfer coefficient, $c_{b}$ is the specific heat capacity of the bed $\left(\mathrm{J} \mathrm{K}^{-1} \mathrm{~kg}^{-1}\right), \rho_{b}$ is the density of the bed $\left(\mathrm{kg} \mathrm{m}^{-3}\right)$ and $S\left(\mathrm{~K} \mathrm{~s}^{-1}\right)$ is the sum of temperature sources and sinks within the bed. These include the energy required to volatilise fuel, and the energy required to evaporate any water present. This equation is subject to boundary conditions for heat flow above and below the fuel bed.

There is a significant temperature gradient over the bed from the surface part nearest the flames through to an effectively static ground temperature a few tens of centimetres under the flame (i.e., fuel bed depth). To simplify the modelling, the fuel bed is broken into two parts, an upper part subject to an upper radiation boundary condition from the flames and a lower part with a lower static boundary condition from the ground. Both layers are taken to be $10 \mathrm{~cm}$ deep in the following analysis. A breakdown of the system is shown schematically in Figure 1.

The flame temperature can be measured experimentally and is assumed to be constant in the model once the fuel has ignited. The ground temperature is set to a nominal $25^{\circ} \mathrm{C}$. Once the fuel bed is ignited, it is assumed to produce heat and linearly decrease in mass uniformly (Viegas et al., 2010, McAllister, 2019), representing internal thermal decomposition processes such as the char pathway, independent of whether volatile gases produced oxidise (i.e. produce flame). 


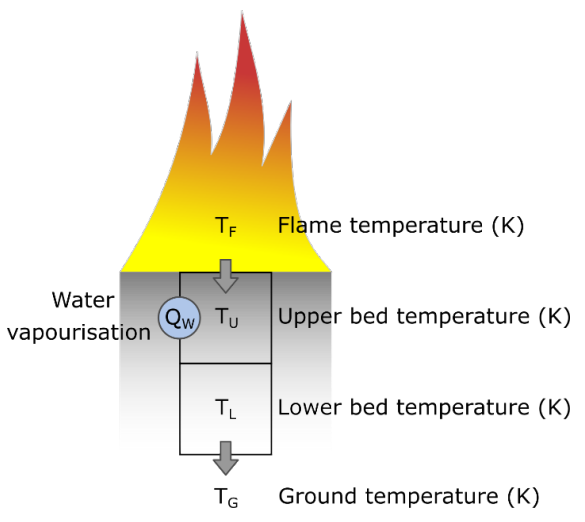

Figure 2. Schematic diagram of fuel bed model.

The heat equation for the upper part of the bed involves radiation transfer from the flame, combustion within the fuel bed and any energy loss through water vaporisation. The change in temperature of the bed due to fuel combustion, $S_{b}$, is given by:

$$
S_{b}=\frac{a H}{c_{b} \rho_{b}} \frac{\partial \rho_{f}}{\partial t}
$$

where $a$ is a coefficient representing the overall combustion energy remaining in the bed, $H$ is the heat of combustion of the fuel $\left(\mathrm{J} \mathrm{kg}^{-1}\right)$ and $\rho_{f}$ is the density of the fuel in the bed $\left(\mathrm{kg} \mathrm{m}^{-3}\right)$. Note $\rho_{b}$ is the bulk density of the bed (the fuel elements distributed within the bed), whereas $\rho_{f}$ is the density of the fuel remaining in the bed (the un-burnt fuel elements distributed within the bed). The bulk density is fixed in the calculation as the product $c_{b} \rho_{b}$ gives a volumetric temperature change for the fuel $\left(\mathrm{K} \mathrm{m}^{-2} \mathrm{~J}^{-1}\right)$, whereas the fuel density $\rho_{f}$ decreases over the simulation as fuel is consumed. The endothermic enthalpy of volatilization of the fuel is $\sim 100$ times smaller in magnitude than the exothermic heat of combustion (Sullivan and Ball 2012) and is neglected in the analysis.

The application of water in the model is assumed to happen instantaneously at time $t_{d r o p}$ as, for example from an aerial water drop. The change in temperature of the bed due to water vaporisation, $S_{W}$, is:

$$
S_{W}=-\frac{\rho_{w}}{c_{b} \rho_{b}}\left(L+c_{w} \Delta T_{w}\right) \delta\left(t-t_{d r o p}\right)
$$

where $\rho_{w}$ is density of water added to the bed $\left(\mathrm{kg} \mathrm{m}^{-3}\right), L$ is the latent heat of vaporization of water $\left(\mathrm{J} \mathrm{kg}^{-1}\right), c_{w}$ is the specific heat of water and $\Delta T_{w}$ is the temperature change require to raise the water to boiling. Note, again, that $\rho_{w}$ is the density of water in the bed and is typically much lower the actual density of water, as this is equal to the mass of water distributed over the volume of the fuel bed. The application of water is modelled using a Dirac delta impulse function $\delta$ applied at time $t_{\text {drop }}$. This impulse function effectively applies an effectively instantaneous temperature drop to the bed representing the sudden addition of water.

Table 1. Physical parameters used in model.

\begin{tabular}{|l|c|l|}
\hline Parameter & Parameter & Value \\
\hline Flame temperature & $T_{F}$ & $1100^{\circ} \mathrm{C}$ \\
\hline Ground temperature & $T_{G}$ & $25^{\circ} \mathrm{C}$ \\
\hline Fuel ignition temperature & $T_{I}$ & $200^{\circ} \mathrm{C}$ \\
\hline Heat transfer coefficient from flame to bed & $h_{f}$ & $100 \mathrm{~J} \mathrm{~s}^{-1} \mathrm{~m}^{-2} \mathrm{~K}^{-1}$ \\
\hline Heat transfer coefficient within bed & $h_{b}$ & $10 \mathrm{~J} \mathrm{~s}^{-1} \mathrm{~m}^{-2} \mathrm{~K}^{-1}$ \\
\hline Heat of combustion of fuel & $H$ & $2 \times 10^{7} \mathrm{~J} \mathrm{~kg}^{-1}$ \\
\hline Heat of vaporization of water & $L$ & $2.26 \times 10^{6} \mathrm{~J} \mathrm{~kg}^{-1}$ \\
\hline Specific heat of fuel bed & $c_{b}$ & $2000 \mathrm{~J} \mathrm{~kg}^{-1} \mathrm{~K}^{-1}$ \\
\hline Specific heat of water & $c_{w}$ & $4179 \mathrm{~J} \mathrm{~kg}^{-1} \mathrm{~K}^{-1}$ \\
\hline Radiation view factor & $\epsilon$ & 0.9 \\
\hline Fraction of combustion energy remaining in bed & $a$ & 0.1 \\
\hline
\end{tabular}


The radiation boundary condition for the flame is given by:

$$
q_{f}=\epsilon \sigma\left(T_{U}^{4}-T_{F}^{4}\right)
$$

where $q_{f}$ is the heat flux on the upper surface $\left(\mathrm{J} \mathrm{s}^{-1} \mathrm{~m}^{-2}\right), \epsilon$ is a radiation attenuation and view factor coefficient, $\sigma$ is the Stefan-Boltzmann coefficient $\left(\mathrm{J} \mathrm{S}^{-1} \mathrm{~m}^{-2} \mathrm{~K}^{-4}\right), T_{F}$ is the fixed flame temperature $(K)$, taken to be $1100^{\circ} \mathrm{C}$ (Wotton et al., 2012) and $T_{U}$ is the upper bed temperature $(K)$. This component is only applied if the bed temperature is above the ignition temperature, with the resulting flames providing the radiative component.

From the above, the heat equation for the upper part of the bed can be approximated by:

$$
\frac{\partial T_{U}}{\partial t} \sim \frac{1}{c_{b} \rho_{b}} \frac{1}{\Delta z}\left(h_{b} \frac{T_{L}-T_{U}}{\Delta z}-h_{f} \frac{T_{U}-T_{F}}{\Delta z}-\epsilon \sigma\left(T_{U}^{4}-T_{F}^{4}\right)\right)+S_{b}+S_{W}
$$

where Eq. (1) has been discretised in the z-direction using the approximation $\partial z \sim \Delta z$, where $\Delta z$ is the thickness of the bed layer (taken to be $10 \mathrm{~cm}$ here). The heat conduction coefficients have been split into the heat conduction coefficient from the fire into the bed, $h_{b}$, and the heat conduction coefficient within the bed, $h_{f}$. These terms are dominated by convection as conduction terms are $\sim 100$ times lower.

The lower boundary has a similar form, although without a radiation inflow component or water vaporisation term:

$$
\frac{\partial T_{L}}{\partial t} \sim \frac{1}{c_{b} \rho_{b}} \frac{1}{\Delta z}\left(h_{b} \frac{T_{G}-T_{L}}{\Delta z}-h_{b} \frac{T_{L}-T_{U}}{\Delta z}\right)+S_{b}
$$

These equations, coupled though $T_{U}$, can be discretised using a simple first order Euler scheme to provide an approximation for the temperature in the two parts of the bed.

The physical parameters used for the models in this report are shown in Table 1. There is considerable uncertainly in some of these factors. The heat transfer coefficient from the flame to the bed is estimated from McAllister and Finney (2014), but the heat transfer coefficient within bed is difficult to determine. The fraction of combustion energy remaining in the bed is likewise difficult to determine. The initial temperature of the fuel was set to a nominal fuel ignition temperature $T_{I}$ of $200^{\circ} \mathrm{C}$. These parameters were chosen to provide a thermal profile within ranges to those observed in fuel beds (Anderson et al. 2010), with a maximum temperature steady-state upper bed temperature of around $600^{\circ} \mathrm{C}$ and a lower bed temperature of around $300^{\circ} \mathrm{C}$. The bed density loss rate was calculated from the above as $0.0625 \mathrm{~kg} \mathrm{~s}^{-1} \mathrm{~m}^{-3}$, assuming linear mass loss (Viegas et al. 2010, McAllister, 2019) and the mass was divided evenly between two $10 \mathrm{~cm}$ layers. This $20 \mathrm{~cm}$ deep bed represented the strata of upper surface fuel (Gilroy et al., 2009) down into the topsoil layer, where the lowest part is at an approximately constant ground temperature. This depth is highly variable being dependent of forest type, productivity and fire history, and $20 \mathrm{~cm}$ is used here only as an example representative value.

Two-dimensional fire spread was modelling using the Spark framework (Miller, 2015), which can handle any number of fireline geometries in different fuel types as well as model firebrands, suppression, radiant heat flux and basic combustion processes. Spark is a model-agnostic fire simulation framework, in that no particular fire behaviour characteristics are implicitly included in the system. The framework provides the basic mechanisms for modelling the stable propagation of a wildfire and the transport of firebrands through the air. The fire behaviour is supplied to the framework by user-defined scripts. These include, for example, scripts for modelling how fires grow in certain fuel types or scripts to define the drag force on a firebrand. These were used here to implement the suppression effects of water, the subsequent heat loss and the ability to suppress the spread of a wildfire.

To implement the bed temperature model in Spark we assumed that once a cell was ignited it burnt with the given mass loss rate until all fuel was consumed. At each simulation time step the temperature in the upper and lower parts of the bed were calculated using Eq. (5) and Eq. (6), keeping track of the current of the current fuel mass, $f_{b}$, in each cell. The McArthur rate-of spread model was used for all fires within this project. The McArthur model was developed for Australian forests and is widely used in operational and risk predictions. The model is given by (Noble et al., 1980):

$$
s=0.0012 F m
$$

Where $s$ is the speed in $\mathrm{km} \mathrm{h}^{-1}, F$ is the Forest Fire Danger Index and $m$ is the fuel load (tonnes ha-1). Eq (8) provides only the frontal speed of the fire. To convert this into a two-dimensional fire spread an elliptical template was used. The length-to-breadth ratio of this template was based on Alexander et al. (1985). 


\section{RESULTS}

\subsection{One dimensional case}

A one-dimensional application of the model to a single point from ignition of the bed to exhaustion of available fuel is shown in Figure 3. Temperatures for the upper and lower bed layers were calculated using Eq. (5) and Eq. (6), where the temperature of the upper bed is shown as a light blue curve and the lower bed is shown as a dark blue curve. No application of water was used in this example. The flame temperature is plotted as a solid light-yellow block for a visual indication of when the flame is active (the bed is above the ignition temperature). The fuel density is plotted as a dark brown line on the second axis. As the fuel reduction rate is linear this is simply a diagonal line here starting from the initial bed density and reducing linearly until the fuel is exhausted.

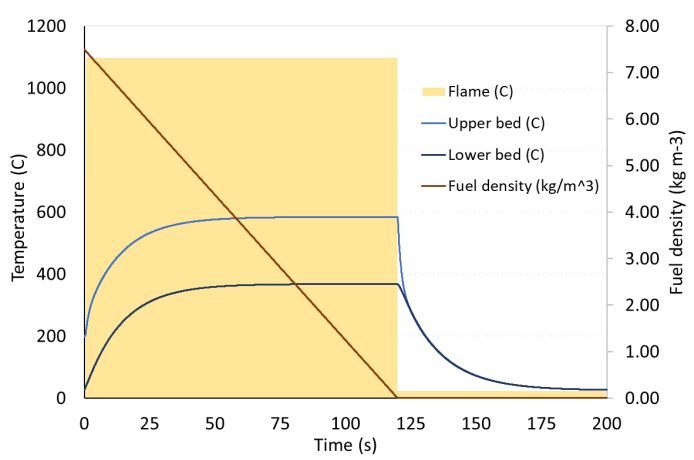

Figure 3. Flame (solid yellow), upper and lower bed temperatures and fuel density against time.

The upper bed heats rapidly though radiation and internal heat generation from combusting fuel, arriving at a steady state of approximately $600^{\circ} \mathrm{C}$ by around $30 \mathrm{~s}$. The lower bed heats from ambient temperature though thermal transfer from the upper bed as well as internal heat generation from the fuel, and cools though heat transfer to the lower ground. After the fuel is exhausted at $120 \mathrm{~s}$ the flame is extinguished, internal heat generation ceases and the bed layers exponentially cool.

Figure 4 shows the same set up but with $1.4 \mathrm{~kg} \mathrm{~m}^{-2}$ water added at $60 \mathrm{~s}$ (the time of the water application is marked by a vertical dashed black line). Two different fuel loads are shown, with a fuel bulk density of $7.5 \mathrm{~kg} \mathrm{~m}^{-3}$ on the left (this corresponds to an area fuel load of $15 \mathrm{t} \mathrm{ha}^{-1}$ distributed over the two vertical fuel layers of $10 \mathrm{~cm}$ each) and $10 \mathrm{~kg} \mathrm{~m}^{-3}$ on the right (corresponding to an area fuel load of $20 \mathrm{t} \mathrm{ha}^{-1}$ ).

The model in this example shows application of the water can suppress a fire in a bed with a fuel density of $7.5 \mathrm{~kg} \mathrm{~m}^{-3}$ (Figure 4, left), subject to the parameters and assumptions used. In this case the fuel bed heats as before, but the heat loss from the water is sufficient to cool the bed to less than the ignition temperature of $200^{\circ} \mathrm{C}$. This extinguishes the flame and causes the upper and lower bed to cool. However, the upper bed temperature can be seen to rise just after the water has been applied (around $50 \mathrm{~s}-60 \mathrm{~s}$ ) due to thermal transfer from the lower bed until the upper and lower bed temperatures are in thermal equilibrium. The temperature of both layers slowly decreases due to internal heat generation (from around $60 \mathrm{~s}$ to $120 \mathrm{~s}$ ) until the fuel is used up (at $120 \mathrm{~s}$ ), after which the bed cools exponentially to the ambient ground temperature.
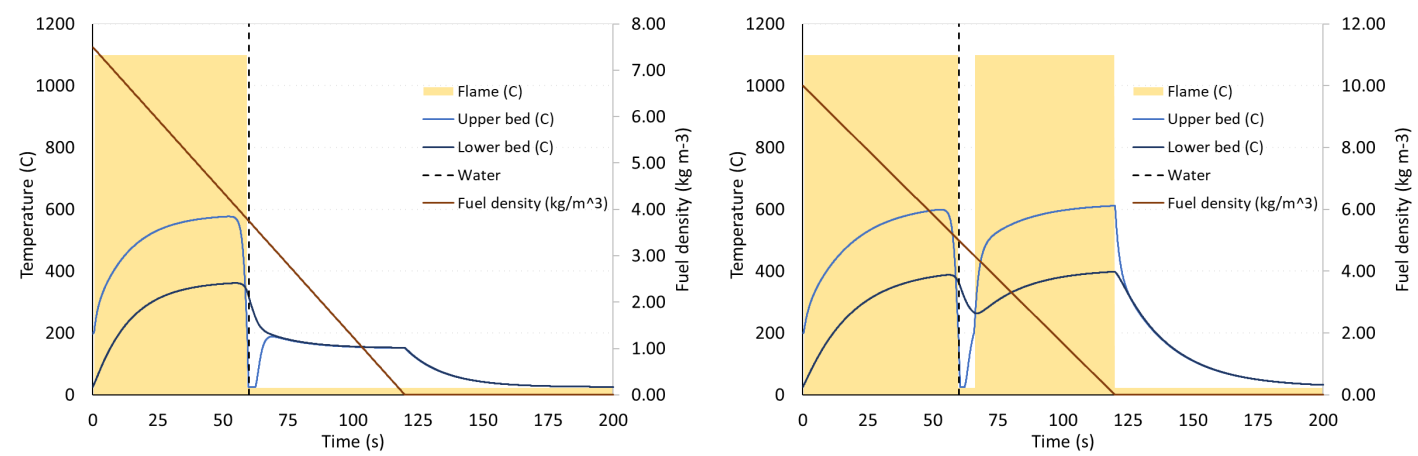

Figure 4. Flame (solid yellow), upper and lower bed temperatures and fuel density against time with $1.4 \mathrm{~kg} \mathrm{~m}^{-2}$ of water added at $60 \mathrm{~s}$. Left: bed density of $7.5 \mathrm{~kg} \mathrm{~m}^{-3}$, where the application of water extinguishes the flame. Right: bed density of $10 \mathrm{~kg} \mathrm{~m}^{-3}$, where the bed is temporarily extinguished but re-ignites. 
For the case of a $10 \mathrm{~kg} \mathrm{~m}^{-3}$ fuel density (Figure 4, right), the model shows the application of water is not sufficient to suppress the fire. In this case the upper bed temperature rises above the ignition temperature after $60 \mathrm{~s}$, re-igniting the fuel. This causes the radiation component from the flames to be applied, Eq. (4), resulting in the upper bed temperature quickly rising back to a steady-state of around $600^{\circ} \mathrm{C}$. As with the case without water application, after the fuel is exhausted the flame is extinguished and the bed layers exponentially cool.

\subsection{Two-dimensional case}

The one-dimensional model detailed in the previous section was applied over a two-dimensional domain using Spark. The domain was divided into $0.5 \mathrm{~m} \times 0.5 \mathrm{~m}$ cells and the bed temperatures were calculated in each cell using Eq. (5) and Eq. (6). The fuel density and amount of water was tracked in each cell. Fire spread was modelled using the McArthur model, Eq. (8), with a Forest Fire Danger Index $F$ of 80 and an elliptical propagation template, as detailed in section 2 . The fire was ignited at a point and developed under a constant westerly wind of $30 \mathrm{~km} \mathrm{~h}^{-1}$ with fuel bulk densities of $10 \mathrm{~kg} \mathrm{~m}^{-3}\left(m=20 \mathrm{tha}^{-1}\right)$ and $12.5 \mathrm{~kg} \mathrm{~m}^{-3}\left(m=25 \mathrm{tha}^{-1}\right)$.

A suppression pattern was applied in this case based on the Gaussian form reported from experimental measurements of aerial suppression drops by Legendre et al. (2014):

$$
\bar{\eta}(y)=0.407 \eta_{\max } \exp \left(-\frac{y^{2}}{2 \lambda_{0}^{2}}\right)
$$

where $\bar{\eta}(y)$ is the mean area coverage $\left(\mathrm{L} \mathrm{m}^{-2}\right)$ along the direction $y$ orthogonal to the drop path, $\eta_{\max }$ is the centerline maximum coverage and $\lambda_{0}$ is the Gaussian width.

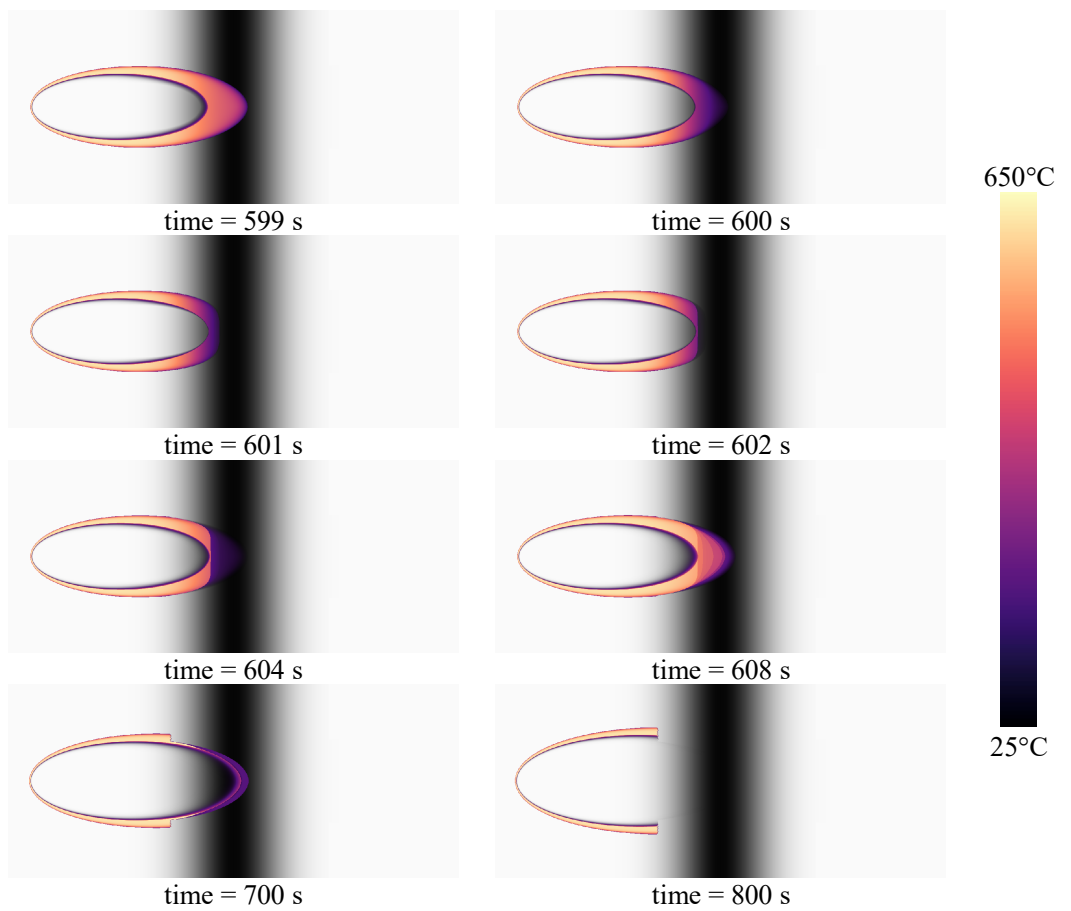

Figure 5. Upper bed temperature for idealized elliptical fire ignited from a point source with a fuel density of $10 \mathrm{~kg} \mathrm{~m}^{-3}$. The grayscale shading represents mass of water per unit area from Eq. (8) where black is $1.42 \mathrm{~L} \mathrm{~m}^{-2}$.

A visualization of the upper bed temperature $\left({ }^{\circ} \mathrm{C}\right)$ for a simulation with a fuel density of $10 \mathrm{~kg} \mathrm{~m}^{-3}$ is shown in Figure 5. The fire develops as an ellipse from the initial starting point. Water was added to the simulation at $600 \mathrm{~s}$ in a vertical strip using Eq. (8), where we used representative spread parameters measured from a Cal Fire S-2T aircraft with $\eta_{\max }=3.5$ and $\lambda_{0}=50$ (Legendre et al., 2014). When water is applied at $600 \mathrm{~s}$ the upper bed temperature immediately drops within the suppression region (shown as grayscale shading proportional to the amount in Figure 5) before recovering at $\sim 608 \mathrm{~s}$. As the front moves into areas containing greater amounts of water the area of the flaming region decreases before the fire is eventually extinguished.

Figure 1 shows a case with a slightly greater amount of fuel, $12.5 \mathrm{~kg} \mathrm{~m}^{-3}$. In this case the suppression does not stop the fire as the burning region not entirely covered by the applied water. The bed temperature at the front of the fire is reduced when water is applied at $600 \mathrm{~s}$, but the temperature at the front of the fire is not sufficiently reduced to extinguish the flame which results in a breakout from suppressed area. 


\section{DISCUSSION AND CONCLUSION}

We have presented and demonstrated a basic water-based fire suppression model based on heat transfer within a fuel bed that can be applied in a spatial wildfire simulator. The model uses a range of physical parameters, some of which are uncertain and require further investigation and measurement through experiments. The model is based on a discretisation of the fuel bed into two layers, one with a radiation-based upper boundary condition and one with a fixed ground temperature lower condition. These are obviously simplification of the complexities of fuel bed combustion but are used here as a first step and for the computational efficiency of only modelling two layers. Further work is required to compare the model behaviour to analytical solution or experimental results, as well as to perform a comprehensive numerical investigation of the model.

Despite these simplifications, the model allows a range of behaviours in a fuel bed to be simulated, namely, temperature rise due to combustion, the ability to reach a realistic steady-state temperature in a physical manner, the ability to allow sudden cooling by the application of water, the coupling and heat loss to the ground and the ability to ascertain whether flaming combustion is sustainable. The work presented here demonstrates this model can be used to investigate the potential effectiveness of fire suppression using water under a range of burning conditions and can be extended to a two-dimensional model suitable for operational predictions.

\section{ACKNOWLEDGMENTS}

We gratefully acknowledge Marc Hartmann and Mark Willcocks from Active Tree Services for funding contributions to this research.

\section{REFERENCES}

Alexander, M.E., Estimating the length-to-breadth ratio of elliptical forest fire patterns, 287-304 in Proceedings of the 8th Conference on Fire and Forest Meteorology, 1985, Detroit, MI.

Anderson W.R., Catchpole E.A., Butler B.W., 2010. Convective heat transfer in fire spread through fine fuel beds, International Journal of Wildland Fire, 19, 284.

Drysdale D., 1985. An introduction to fire dynamics. Wiley.

Hansen, R., 2011. Estimating the amount of water required to extinguish wildfires under different conditions and in various fuel types, International Journal of Wildland Fire, 21, 778.

Gilroy, J., Tran, C., 2009. A New Fuel Load Model for Eucalypt Forests in Southeast Queensland. Proceedings of the Royal Society of Queensland, 115, 137.

Legendre, D., Becke, R., Alméra, E., Chassagne, A., 2013. Air tanker drop patterns. International Journal of Wildland Fire, 23, 272.

McAllister S., Finney M., Convection Ignition of Live Forest Fuels, in Fire Safety Science - Draft Proceedings of the Eleventh International Symposium, 2014.

McAllister S., 2019. The Role of Fuel Bed Geometry and Wind on the Burning Rate of Porous Fuels, Frontiers in Mechanical Engineering, $\mathbf{5}$.

Noble, I.R., Bary, G.A.V., Gill, A.M., 1980. McArthur's fire danger meters expressed as equations. Australian Journal of Ecology, 5, 201-203.

Plucinski, M.P., 2019. Fighting flames and forging firelines: wildfire suppression effectiveness at the fire edge. Current Forestry Reports, 5, 1.

Miller, C., Hilton, J., Sullivan, A., Prakash, M. (2015), Spark - A bushfire spread prediction tool, International Symposium on Environmental Software Systems, 262.

Sullivan, A.L., 2017, Inside the Inferno: Fundamental processes of wildland fire behaviour. Part 1: Combustion chemistry and energy release. Current Forestry Reports, 3, 132.

Sullivan, A.L., Ball, R., 2012, Thermal decomposition and combustion chemistry of cellulosic biomass. Atmospheric Environment, 47, 133.

Viegas, D. X., Almeida, M., Miranda, A. I., Ribeiro, L. M, 2010. Linear model for spread rate and mass loss rate for mixed-size fuel beds, International Journal of Wildland Fire, 19, 531.

Wotton B.M., Gould J.S., McCaw W.L., Cheney N.P., Taylor S.W., 2012. Flame temperature and residence time of fires in dry eucalypt forest, International Journal of Wildland Fire, 21, 270. 